\title{
ОБЩАЯ ПЕДАГОГИКА
}

УДК 159.22

\section{ПЕДАГОГИЧЕСКИЕ КОМПЕТЕНЦИИ УЧИТЕЛЯ: ПРОБЛЕМА МЕТОДОВ И ФОРМ ОБУЧЕНИЯ В ОБРАЗОВАТЕЛЬНЫХ ТЕХНОЛОГИЯХ БУДУЩЕГО}

\author{
В.К. Баринов, Ю.А. Самоненко
}

Филиал ГБОУ ВО Московской области «Университет «Дубна»Дмитровский институт непрерывного образования, Дмитров

DOI: $10.26456 /$ vtpsyped/2020.4.084

Рассматриваются результаты эмпирической проверки эффективности технологии опережающего обучения учащегося на основе личностного образовательного проекта, структура которого представлена моделью «древа» целей образования. Работа над проектом позволяет оптимизировать программы основного и дополнительного образования относительно каждого ученика, а также определить его самостоятельную работу. Обоснованы методы и формы, способствующие развитию ученика как субъекта учебной деятельности, приемы формирования мыслительных способностей, осознания им общественных и личностных целей образования. Обозначены направления интеграции видов образования учащихся при подготовке к профессиональной деятельности в сфере науки, высоких технологий и других областях труда с высоким интеллектуальным содержанием.

Ключевые слова: непрерывное образование, скаффолдинг, личностный образовательный проект, опережающее знание, методологическая компетентность, системное мышление, умение учиться, дополнительное образование.

Идея опережающего обучения высказывалась давно. Во многих исследованиях проблему повышения эффективности предметного обучения связывали с предварительным уяснением более широкого контекста знаний. К ним относятся разработки, опирающиеся на идеи зоны ближайшего развития (Л.С. Выготский), проблемного обучения (Дж. Дьюи), скаффолдинга, среди которых в рамках нашей проблематики отметим работы, посвященные подготовке учителей к применению этого перспективного метода [1]. По существу, об опережающей функции обобщенных схем ориентировочной основы действий идет речь в теории формирования умственных действий и понятий (П.Я. Гальперин), теории установки (Н.Д. Узнадзе), контекстного обучения (А.А. Вербицкий), использования в обучении укрупненных дидактических единиц (П.М. Эрдниев), теоретического обобщения (В.В. Давыдов). Работы по формированию системной ориентировки в предмете предложены научной школой профессора МГУ 3.А. Решетовой [6]. В исследованиях по заявленной тематике мы 
придерживались приоритетных положений проектирования образовательных систем, провозглашенных в проекте «Школа-2100», разработанном под руководством академика А.А. Леонтьева [5].

Новым в наших работах является предварительная экспозиция учащимся модели развития, ядром которой является древо целей образования, описание которого дано в предшествующей части работы [2]. На основе модели участники образовательного процесса могли наметить перспективные линии самореализации молодого человека как в профессиональной деятельности, так и по жизни в целом. Методы, используемые в эмпирической части работы, были традиционными для педагогических исследований: наблюдение, рефлексивная беседа, формирующий эксперимент, анализ продуктов деятельности, экспертная оценка, самооценка учащихся.

Стратегия жсизненных планов. Личностный образовательный проект

Известно, что большинству молодых людей свойственно задумываться о своем будущем, представлять себя успешным, сильным, уверенным в себе. Этот образ создается под влиянием жизненных впечатлений, идентификации с экранными и литературными героями, работы воображения, примеров из ближайшего окружения. С другой стороны, молодые люди хотят разобраться в причинах неудач в учебе, общении и других обстоятельствах и, соответственно, возможностях исправления неблагоприятного положения дел. Личностный проект призван придать реалистичность этим устремлениям. Из этого исходила наша программа работы с учащейся молодежью.

Формирующая часть опиралась на междисциплинарный курс дополнительного образования «Как мы познаем мир и самих себя». Особенность его содержания состоит в том, что курс предполагает значительную вариативность в зависимости от контингента слушателей - будущих участников проекта (школьники, студенты СПО, учителя, родители). Инвариантной его частью было содержание, относящееся к раскрытию структуры «древа целей образования». Соответственно этому строились разделы курса.

Во введении были обозначены цели и задачи курса, а также в общих чертах определялось содержание понятия «личностный образовательный проект».

Раздел 1 «Человек как субъект деятельности» посвящен исторической роли коллективного труда в становлении субъектаиндивида (и в частности, своей собственной субъектности).

Раздел 2 «Мышление - главная способность человека» посвящен вопросам развития этой способности в обучении.

Раздел 3 «Общественные и личностные цели образования» раскрывает направления приложения сил молодого человека в ближайшей и отдаленной перспективах. 
И еще об одной особенности программы курса. Содержание его разделов изучалось не друг за другом, а параллельно. Кроме того, рабочая программа увязывалась с материалом тех учебных дисциплин, которые в данный момент изучались в школе, и вызывала наибольший интерес, или напротив, представляла наибольшие трудности. Отдельные темы курса проводили подготовленные учителя-предметники.

Во введении учащиеся знакомились с понятием личностного образовательного проекта. Ставилась цель сформировать у учащихся установку для включения этого понятия в сферу своих жизненных интересов, связав смыслы текущей учебной работы и перспективы успешной самореализации в отдаленном будущем. Материалом являлись биографии людей, в которых описывалось, как замысел молодого человека реализовался в его последующей жизни (self made man - человек, сделавший себя сам). В результате обсуждения и выполнения самостоятельных работ выявились общие контуры развития творческой личности, в которой успех обусловил не обязательно удачное стечение внешних обстоятельств, а был следствием большой внутренней работы над собой. Эти контуры задают измерения «пространства жизни», в котором происходит конкретизация траектории личностного развития. В ходе дискуссий древо целей образования выступало, с одной стороны, как теоретическое понятие, а с другой, оно не было отвлеченной, абстрактной конструкцией, поскольку отображало собой «древо жизни» - обобщенную модель поколенческой истории человеческих судеб. Древо целей выступает для учащегося объективацией его мечтаний, антиципацией будущего, являясь стимулом его активности. Для педагога это схема помогает найти общий язык с учеником, направлять его поисковые действия по мере возникновения проблемных ситуаций. Древо целей служит средством самоанализа учебной работы, позволяет участникам образовательного процесса констатировать сделанное, определить направления предстоящих усилий для достижения промежуточных целей или же внести коррекции в ранее намеченные цели. К обсуждению древа целей на протяжении цикла обучения, как показывает наш опыт работы с этим понятием, необходимо обращаться не раз - по мере того как обогащается жизненный опыт ученика и появляется новый материал для рефлексивного анализа.

Представление о личностном образовательном проекте мы относим к категории опережсющего знания, поскольку его структурные компоненты дают наглядное представление о содержании различных видов активности, в которые целесообразно включиться в дальнейшем ученику.

Представление о себе, как субъекте деятельности - основа рефлексивного мировоззрения

Занятия по темам 1-го раздела проводились в формах бесед и 
деловых игр с опорой на жизненный опыт учащихся и конечном счете были нацелены на умения анализировать свои субъектные качества. Давались лексические определения понятиям, характеризующим субъектные состояния в соответствие с эргатической моделью субъекта деятельности («идеолог», «руководитель», «исполнитель», «стратег»). Описывались психологические портреты людей как с гармонично развитым, так и с деформированным профилем субъектных состояний, их характерные жизненные проявления. Рефлексивная беседа после краткого введения по теме «Древо жизни», продолжалось в форме деловой игры_постановкой перед слушателями интригующего вопроса: «На какое дерево ты похож?». Молодые люди оценивали себя с точки зрения качественной выраженности основных субъектных состояний. Договаривались о порядковой шкале для «количественной» оценки субъектных качеств. Необходимо было перейти от эмоциональных оценок себя и друг друга (что нередко случалось в начале бесед) к анализу жизненных поступков, удач и досадных промахов. Условились, что высшая оценка 10 баллов присваивалась литературному персонажу, киногерою или просто лицу, знакомому присутствующим, у которого то или иное качество было, по общему мнению, развито в высшей степени. «Идеолог» (на занятиях эта субъектная позиция именовалась ещё как «царь в голове») выступал как человек, увлеченный какой-либо идей, ставшей ведущей в его жизни, либо предлагающий окружающим интересные для совместного воплощения идеи. Позиция «руководитель» рассматривалась с точки зрения способности человека к саморуководству, готовности к волевому поступку, умению сосредоточиться, противостоять конфликтным ситуациям, переносить тяготы жизни и т.п. «Исполнитель» как субъектная позиция отмечается у персоны высоким баллом в случае виртуозного выполнения физических или интеллектуальных действий (в противном случае о человеке говорят «растяпа», «неумеха» и т.п.). «Стратегическая» позиция соответствовала высокому месту в рейтинговой шкале, если человек правильно предвосхищал исход ситуации, в то время как большинство в нее вовлеченных людей затруднялись предсказать результат. Низшим баллом (1-2 балла) оценивается маловыраженная субъектная характеристика человека. Каждый участник оценивал в себе названные субъектные характеристики, степень их выраженности в том или ином виде активности. Далее профиль сравнивался со стандартным профилем «нормального», с точки зрения присутствующих, уравновешенного молодого человека с равной выраженностью всех субъектных позиций (такой профиль представлял собой квадрат с вершинами на осях прямоугольной системы координат, где на осях отложена в условных единицах выраженность той или иной позиции [2]. Обсуждались случаи существенных деформаций профилей. Так, 
гипертрофия идеологического полюса при нормальной выраженности остальных, означает, что перед нами лидер, мессия, проповедник, предприниматель и т.п. Если же идейная сторона преобладает, а все остальные присутствуют в незначительной степени, то мы имеем дело с фанатом (например, ярым футбольным болельщиком, ортодоксальным верующим, идолопоклонником популярного артиста, некритичным приверженцем одной научной концепции). Точно так же ярко выраженное состояние внутреннего «руководителя» может означать разное. В случае достаточного проявления и других субъектных состояний мы имеем дело с настойчивым человеком, в противном случае, когда эти состояния слабо выражены, - с упрямым. Если у человека преобладает стратегическая составляющая при относительной норме остальных, то имеем вдумчивого субъекта-аналитика, но если остальные позиции оказываются в дефиците, то чаще всего мы имеем дело с человеком, имеющем прожектёрские наклонности. Подобным образом, по совокупной оценке субъектных состояний, которые устойчиво проявляются в общении и деловой жизни человека, за ним закрепляются характеристики, принятые в обиходной речи: «фантазер», «трудоголик», «одержимый», «лентяй», «демагог», «резонер» и проч. Представление о себе как о субъекте деятельности является основой рефлексивного отношения к себе. Именно с осознания своих субъектных качеств у наших слушателей начинался процесс самоопределения как будущего члена коллективного субъекта. Эта тема перманентно звучала в курсе, став привычным компонентом его психологической культуры, выполняющим опережающую функцию по отношению к другим гуманитарным обретениям молодого человека.

«Я мыслю - значит, я существую» (Р. Декарт). О формировании главной способности человека

Дальнейшее усвоение понятия «древа жизни» и соответственно «древа целей» образования происходит через раскрытие понятия «мышление». Об этой высшей психической функции почти не упоминается в образовательных стандартах. Возможно, это связано с трудностями доступного изложения содержания этого понятия участникам образовательного процесса. Но здесь коренятся трудности рефлексивного сопровождения познавательных процессов. В наших курсах соответствующую тему мы начинаем с девиза, знакомого каждому школьнику: «Математика - гимнастика ума». В обсуждениях смысла этого выражения нередко добавляют: «Ту же функцию должны выполнять и другие предметы». Яркий образ, сравнивающий умственное совершенствование с гимнастикой, кажется учащимся убедительным. Однако в нем заложена коварная недосказанность. Поэтому предлагалось перейти к обсуждению еще одного образного сравнения. Слушателям задается вопрос: «Кто быстрее справится с большим объемом земляных 
работ: тренированный землекоп, вооруженный лопатой, или тщедушный машинист экскаватора, управляя рычагами мощной машины?». Ответ однозначен: конечно, обладатель мощной техники. Теперь переформулируем вопрос, сместив его в сторону «интеллектуальной гимнастики». Сравним тренированный интеллект победителя викторины типа «Что? Где? Когда?» и автора оригинального изобретения. Теперь от категоричного ответа на вопрос, у кого из них лучше организовано мышление, мы воздержимся. У первого обширность сведений может быть гораздо больше, чем у сосредоточенного на одной проблеме изобретателя. Но «ходячая» энциклопедия не станет источником нового открытия. А нам, как правило, важнее второе, то есть мыслительная работа, сдвинувшая с места назревшую проблему. Но в этом сопоставлении мы невольно допустили, что сравниваемые персоны пользуются средствами умственной деятельности. Насколько оправдано это предположение? Его справедливость уже не одно столетие как утвердилась в умах ученых и нашла свое развитие в важнейшей отрасли философского знания - методологии научного познания. Оказывается, умственные упражнения не всегда приводят к развитию мышления. Здесь решающим обстоятельством, как и в случае с землекопом, является действенность используемых средств интеллектуального труда.

С этим утверждением обычно соглашаются в научной дискуссии. Но учителя, имевшие отношение к нашей исследовательской программе, сначала высказывали опасение о возможностях школьника освоить этот достаточно сложный материал. Сомнение в посильности школьника овладеть научной методологией имеет под собой основание. Подобная инновация была осуществлена на практике, когда в середине прошлого столетия в учебный план школы ввели такой предмет, как логика. Результаты были неутешительны. Эта дисциплина не заняла равноправного места в ряду других школьных предметов. Также не увенчались успехом попытки «выучить» логику на младших курсах вузов. Но данный конфуз с этим предметом показал лишь дидактическую ограниченность формально-логического подхода к изучению этой области знаний. Свою несостоятельность показала лишь репродуктивная модель изучения основ методологии как специального учебного предмета.

Другим резоном не ставить такой непосильной образовательной цели было соображение, что основными логическими операциями, такими как сравнение, подведение под понятие, выведение следствия, исключение третьего и т. п., человек и так овладевает в жизненной практике, совершая соответствующие умственные действия тысячи раз и в конце концов овладевая ими на интуитивном уровне. С этим доводом следует отчасти согласиться. Но ситуация осложнится, если 
предметом интеллектуальной деятельности предстанет не хорошо освоенное житейское представление, а в качестве такового выступит новое для учащегося идеальное понятие. К тому же и метод работы с ним также может иметь высокую степень абстрактности. Именно такая ситуация имеет место при использовании научных методов, зачастую относящихся к сфере философских знаний. Их нельзя показать, образно говоря, «на пальцах». В педагогике эти трудности возникают, когда преподаватель пытается помочь учащемуся в затруднительной ситуации, предлагая «наводящий вопрос» или «подсказку». Педагогу приходится в этом случае импровизировать, подстраиваться каждый раз под новую проблемную ситуацию, и вместе с тем он недостаточно уверен, что учащийся «схватил» плодотворную мысль. Ситуация еще более усложняется в попытках вовлечь в работу не одного ученика, а вести разговор с группой слушателей.

Альтернативой методу проб и ошибок является формирование дисциплины мышления учащегося путем усиления его методологической компетентности. Именно такую задачу поставили авторы при разработке приемов усвоения школьниками основ методологии научных знаний. Приведем примеры, поясняющую эту идею, из авторского варианта школьной программы физики, многократно проверенной на контингентах учащихся разного уровня исходной подготовки.

Метод «выводного знания». Поясним его содержание примером. Так, среди общенаучных понятий высокий статус занимает входящее в содержание всех школьных дисциплин понятие «отношения». Только в разделе механики ученик сталкивается с несколькими удельными физическими величинам, такими как скорость, плотность, давление, которые «порождаются» из основных физических величин путем их отношения. При этом учащийся не всегда осознает общий характер их происхождения, поскольку его внимание смещено на интерпретацию того явления, которое изучается в конкретной теме. Иное дело, когда понятию «отношение» уделено специальное внимание. Метод предполагает актуализацию ранее изученных семи основных понятий механики, таких как протяженность $(L)$, площадь $(S)$, объем $(V)$, время $(t)$, масса $(m)$, сила $(F)$, энергия $(E)$. Затем в таблицу заносятся их парные отношения. Соответственно, получается 49 производных величин. Среди них попадаются хорошо знакомые, такие как упомянутые скорость пространственного перемещения, давление, плотность, мощность, коэффициент полезного действия. Но в такой формальной табличной записи отношений есть и другие, о которых ничего не сказано в учебнике. Есть ли в них какой-либо физический смысл? Ответ положительный, и учащимся по силам самостоятельно найти его. Оказывается, скорость может быть отнесена не только к характеристике пространственного перемещения. Можно говорить и о скорости 
изменения площади, объема, силы. Конкретный физический смысл есть и в отношении однородных физических величин. Как показывает опыт, на каждую формальную запись отношения найдется не одно природное явление, характеристикой которого служит именно это отношение. Эти «мини-открытия» с воодушевлением делают сами школьники.

Таким образом, в понятийной сфере учащегося устанавливается движение навстречу друг другу понятий житейских и научных, а само понятие «отношение» выступает как закон порождения теоретического знания, о необходимости чего в обучении в свое время говорил Л.С. Выготский. Явление самостоятельного открытия физической величины является примером «живого знания», особую ценность которому придавали многие мыслители [3]. Здесь присутствует очевидная связь академического знания с жизнью. Понятие выступает как эмпирическое, принадлежащее конкретной области знания. Но одновременно имеет место обобщение: школьник усваивает понятие «отношение» как категорию, на которую он может опираться для вывода новых теоретических понятий - и не только в физике, но и в других предметных областях. Аналогичным образом происходит освоение и других общенаучных понятий, таких как сохранение, симметрия, дополнительность, обратимость и т.п. [7].

«Придумай задачу». Этот метод дает существенное повышение мотивации и развивающего эффекта. Прием побуждает творческую активность. В отличие от привычной позиции ожидания вопроса от учителя, учащийся становится в позицию субъекта учебной деятельности. Например, учебным заданием предполагается, что ключом к решению проблемы послужило бы то или иное общенаучное понятие. Так, учащемуся, уяснившему понятие «симметрия» на материале геометрии, требуется обнаружить симметричность в объектах иной природы (поэзия, биология, социальные явления и т.д.) и разработать самостоятельно задачную ситуацию из этих областей знания. Принцип «обратимости» природных процессов лежит в основе создания теоретических моделей явления (обратимость луча в оптике, восстановление экосистем, химических реакций, возврат к нормальной жизни людей после социальных катаклизмов). От учащегося ожидается трактовка подобных явлений с опорой на законы внутренних процессов конкретных предметных областей (физики, биологии, химии, социальных наук), вскрывающих их сущность, которые позволят обобщить эти картины из разных предметных областей, назвав общенаучное понятие, к которому они относятся (в приведенных примерах - «симметрия», «обратимость» и т.д.). Конечно, для обсуждения проблемной ситуации ученик должен опираться на предметные знания в объеме школьного курса, хотя зачастую познавательная мотивация выводит ученика за ограничительные рамки учебной программы. 
Другой пример. Философские категории «закономерность» и «случайность» преодолевают в сознании учащихся свою абстрактность, когда для каждого из противопоставляемых явлений надо найти генетические основания его происхождения. Например, со слушателями обсуждаются два вопроса. Первый: почему Луна движется по круговой орбите вокруг Земли, а вместе с Землей они движутся вокруг Солнца также по орбите, близкой к круговой? И второй вопрос: почему Луна и Солнце при наблюдении с Земли имеют одинаковой угловой размер $\left(0,5^{\circ}\right)$ ? Ответы на эти вопросы не столь уж сложны. В одном случае поведение тел объясняется законами небесной механики, во втором случайным совпадением геометрических размеров этих тел (Луны и Солнца) и расстоянием между ними и Землей. В других ситуациях ответить на подобный вопрос, особенно если он касается социальных, экологических или психических явлений, достаточно сложно. Примеры человеческих судеб или общественных катаклизмов для обсуждения этой тематики можно привести на материале каждой учебной дисциплины.

Текстовые задачи «исследовательского типа». Эти задачи предполагают различные варианты ответов в зависимости от численного соотношения заданных в условии величин. Приведем пример достаточно простой задачи этого типа, служащей, как правило, для уяснения учеником смысла вопроса задач этого типа. Вопрос задачи: «В каком фазовом состоянии окажется вещество, если смешать лед и воду и между ними произойдет теплообмен?». Очевидно, здесь три возможные записи ответа, предполагающие, что в результате теплового обмена получится лед (капля воды попадает на глыбу льда), только вода (маленький кусочек льда бросают в ведро теплой воды) и третий вариант (вода и лед смешиваются при нулевой температуре). Текстовые исследовательские задачи превращаются в достаточно непростое теоретическое построение модели и ее последующее исследование, где количество вариантов поведения системы значительно больше, чем в приведенной задаче-инструкции. Наша практика показывает, что задача такого типа на школьном материале часто является непосильной даже для студента-физика. А вот школьник с ней справляется. В чем же дело? Школьник овладел процедурами системного анализа такой сложной многофакторной ситуации и ее модельным представлением, т. е. адекватным средством деятельности. Это, образно говоря, и есть «рычаги» мощной машины из вышеприведенного примера с копкой земли. Подобные задачи моделируют реальные профессиональные ситуации, понимание которых требует владения системной методологией. Задачи этого типа характерны для специалистов абсолютно всех видов деятельности: экономистов, технологов, экологов, медиков, управленцев.

Задачи с недостающими, избыточными или «запрашиваемыми» данныли. Задачи этого типа прямо работают на формирование 
системного подхода к анализу ситуации. Такие задачи типичны для реальных научно-производственных и управленческих ситуаций, когда, как правило, нет достаточных исходных данных для принятия решения и необходимо сделать соответствующие запросы. В задачах этого типа условия не ограничивают поисковые действия ученика и в то же время оставляют возможности для применения учителем наводящих вопросов, подсказок. Здесь широкое поле для вовлечения учащихся в проблемные ситуации. Обсуждение этих вопросов учителями проводится в контексте темы «зоны ближайшего развития». Приведем пример такой задачи, предлагаемой ученику для уяснения замысла задач этого типа.

Велосипедист, двигаясь по горизонтальному участку шоссе, может развить скорость до $36 \mathrm{\kappa м} /$ час. Сможет ли он преодолеть подъем на дороге с перепадом высоты в 7 метров?

Практика показывает, что большинство учащихся быстро дают отрицательный ответ на основе привычного алгоритма, приравняв кинетическую энергию велосипедиста у подножья подъема и потенциальную энергию тяготения на его вершине. Но если сделать предположение, что длина подъема равна, например, 50 метрам и велосипедист во всю силу крутит педали, а не только продолжает движение в силу инерции, то категорический ответ ученика окажется неверным и для правильного ответа следует уточнить еще некоторые данные.

Система единии измерения «твоего» имени. Начинаем со знакомого учащимся положения. Как известно, за тройку основных единиц измерения в механике принято брать размерности протяженности, времени и массы. Размерности остальных физических величин могут быть получены с помощью математического выражения их связей и отношений с основными величинами, заданными определениями или физическими законами. Приняты также эталонные единицы измерения. То, что для измерения протяженности используются различные меры, школьникам хорошо известно. Так, кроме основных и производных единиц метрической системы ученикам известно, что расстояние можно измерить в футах, ярдах, милях, в «попугаях», «днях пути». Оказывается, выбор этих единиц носит условный характер и принципиально имеет право на существование такая единица измерения протяженности, как собственный рост. Также единицей, привязанной к «самому себе» является масса собственного тела, а единицей отсчета времени - период биения сердца. Ставится на первый взгляд «несерьезная» задача - построить систему единиц измерения своего имени и сравнить ее с принятой международной системой измерения, а также с системой, которую создаст сосед по парте. (Забавно будет сравнить систему единиц, где силы измеряются в «катях» а энергия - в «вовах»!) На самом деле подобная работа выполняет важную мировоззренческую функцию. В одних случаях она открывает школьнику 
объективность наших научных знаний о мире, где господствуют константные отношения - к примеру, известные мировые константы. В других демонстрирует условный характер многих понятий, как в вышеприведенном примере с выбором системы измерений физических величин. Есть и устойчивые понятия, которые порождены заблуждениями, но воспринимаются как отражающие истинную природу вещей.

Системная методология учебного предмета. Во многом мышление добросовестного учащегося формируется в процессе его деятельности с учебным материалом. Учебные действия ученика отражают структуру и логические связи изучаемого материала. Принятые в дидактике принципы построения предмета - линейный, ступенчатый и концентрический - основаны на формально логическом подходе к изложению учебного материала. Исторически этот было следствием мировоззренческих установок ученых в эпоху становления научного сознания. Стихийно возникающие системные представления интерпретировались их носителями как сверхчувственные идеи, обретаемые в моменты божественного откровения. Что касается «вещного» мира, то его описание в литературе педагогического назначения следовало тем же правилам, что и в науке, где господствовал аналитический метод. Например, в средние века то, что мы называем механикой, представляло совокупность разрозненных знаний, необходимых в профессиональном труде ремесленников: каретника, оружейника, корабела и т.п. Исаак Ньютон в стремлении преодолеть эту ограниченность разработал научную концепцию механики. Связь силы и движения материальной точки стала исходным пунктом описания сложного движения взаимодействующих тел. В этой аналитической парадигме заработала наука, и ее модель восприняла система образования. Так, в традиционном курсе теоретический материал преподносится в соответствии с требованиями формальной логики, следуя правилу «от простого к сложному». В учебных программах это означает последовательное освоение относительно простых элементов знания, затем их соединение внутри тем и разделов учебной дисциплины. Прямым результатом обучения является предметный компонент, побочным - усвоение формально-логических связей и некоторых методологических умений. Однако этот полезный результат обучения не исчерпывает возможности учебного предмета. В последнем заложен более глубокий развивающий ресурс. В наших работах была поставлена задача использовать потенциал этой дидактической единицы для формирования системной ориентировки как в естественнонаучной картине мира, так и в сфере мыслительных процессов. Для этого сам учебный предмет должен выступить как образец системной организации, раскрывающий себя в логике системного метода, подобно тому как аналитическое мышление 
формируется в традиционном обучении благодаря процедурам формально-логического метода. Это прежде всего отразилось на учебной программе, которая стала текстовым приложением к основному документу - концептуальной схеме учебного предмета [7].

Концептуальная схема задает границы изучаемого предмета, демонстрирует учащимся его внутреннюю упорядоченность, фиксирует основные элементы содержания учебного предмета, их связи и отношения в виде законов предметной области. Схема раскрывает перспективы изучения представленного материала, позволяя обозначить возможные траектории познавательного продвижения в нем, является ориентировочной основой преобразовательных действий при решении задач соответствующей предметной области, выступает эффективным инструментом актуализации уже усвоенных учащимися знаний. Концептуальная схема открывает возможность изучать учебный предмет сообразно его структуре, двигаясь в направлении как от «простого к сложному», так «от сложного к простому», позволяя изучать предмет в его системном представлении. Концептуальная схема выступает как опора, логически связующая новые для учащегося знания в общую систему учебного предмета. Рациональное использование концептуальной схемы в ходе учебного процесса направлено на то, чтобы учащийся не «потерялся» в частностях учебного предмета, а сумел встроить и интерпретировать каждый элемент предметного знания в системе базовых понятий. Такая ориентировка обеспечивает понимание учащимися материала учебного предмета, структурную упорядоченность его внутренних и внешних связей, дает возможность многоаспектных интерпретаций его содержания.

Таким образом, для усвоения комплекса методологических знаний нет необходимости вводить отдельный предмет, в рамках которого будет изучаться новое содержание. Для решения этой дидактической задачи целесообразно «распределить» формируемые методологические понятия между учебными дисциплинами, материал которых наиболее пригоден для отработки такого рода инновационного содержания. Наши данные подтверждают известный факт: будучи освоенным на одной дидактической единице, метод или другое методологическое понятие могут быть перенесены на другую дидактическую единицу (раздел или учебный предмет). Здесь открывает возможность значительная экономия учебной нагрузки, поскольку содержание общенаучного уровня, адресованное школьнику, содержит всего несколько десятков понятий, то есть несопоставимо меньше, чем количество предметных понятий, подлежащих усвоению в соответствии с программами всех учебных дисциплин, изучаемых в школе. Каждое из этих методологических понятий не ложится бесполезным грузом на память учащегося, а является действенным инструментом в получении 
выводного знания и решении задач. (Уместно напомнить слушателям притчу о преимуществе самому пользоваться удочкой, нежели ожидать улов от того, кто умеет это делать.) Опасение в том, что предметные знания не будут освоены из-за дефицита времени, неоправданны. Напротив, обоснованным утверждением является то, что учебные затруднения учашцихся связаны как раз с отсутствием методологической культуры. Все еще бытующая «зубрежная» установка ученика, в свою очередь, снижает его интерес к предмету, сводит на нет привлекательность его содержания для вовлечения ученика в творческий процесс, формирует неприязнь к учебной дисциплине, является источником стрессовых состояний учащихся. При правильной методике введения методологических понятий не только не возникнет дефицита времени, необходимого для изучения предметного материала, но и будет достигнуто его уверенное усвоение, причем как в понимании теоретического материала, так и при решении задач, предусмотренных программами учебных предметов.

Естественно, методологическая культура является важнейшей составляющей опережающего знания. Возможностями ее формирования озабочены многие специалисты в области дидактики и методики обучения. Например, исследования Н.В. Кочергиной выполнены на материале школьной физики для профильных классов [4]. Наши разработки рассчитаны на возможности учащихся массовой школы, носят междисциплинарный характер, нацелены на формирование методологических знаний в системе педагогических установок школьника. Соответствующие компетенции показали слушатели, принявшие участие в особом мероприятии - цикле проведенных друг для друга «пробных» уроков. Последующий их разбор показал появление у значительной части слушателей педагогических умений, обнаруженных как при работе с ровесниками, так и обращенных к самим себе.

Общественные и личностные цели образования

Этот раздел программы посвящен проблематике самоопределения учащихся, выбору конкретных планов самореализации, представленных «ветвями» на модели «древа жизни». Нами замечено, что вовлеченность молодого человека в процесс самоопределения часто сопровождается смысловой «инверсией» видов образования: дополнительное образование становится основным в жизни учащегося, а основное образование, напротив, выступает дополнительным к тому, которое необходимо лишь для реализации личностного образовательного проекта. Для большинства учеников становится характерным прагматичное отношение к своему образованию; важным становится только то, что имеет значение для будущей жизни. Тема «Какие таланты мне пригодятся в будущей жизни» вызывает значительный интерес у слушателей. Здесь осознавались возможные источники их 
эмоционального неблагополучия. Работа над личностным образовательным проектом служит в такие периоды хорошим психотерапевтическим средством. Кризиса можно избежать, если поисковые действия подростка направить в русло, адекватное причинам его возникновения. В нашей работе с учащейся молодежью их внимание направлялось на необходимость осознания своих субъектных качеств. Ответ на вопрос самому себе «На какое дерево я похож?» возвращал их к необходимости снова и снова давать рефлексивную оценку обстоятельствам свой жизни, отделяя события «неодолимой» силы от ситуаций, где их инициатором выступил сам учащийся.

Развитие профессиональных способностей и - как итог - успех профессионала в деловой карьере должны соответствовать восхождению по «древу жизни». Талант - это плод древа жизни и, соответственно, усилий человека, приложенных для своего образования. Кроме того, центральной идеей, которую мы старались донести до слушателей, была мысль, что не все способности даны человеку от рождения; можно говорить лишь о задатках. Известно, что способности развиваются в деятельности, причем именно в той деятельности, в которой они и востребованы. Помимо необходимости сосредоточить усилия в избранной сфере деятельности необходимо уберечься от соблазна чрезмерно широкого охвата направлений самореализации. Самоограничение, как это ни странно, также требует активного душевного состояния.

Модель «древа жизни» нуждается в представлении и о соответствующей питательной среде. В качестве таковой выступает социально-экономическая и культурно-историческая среда, в которой развивает свой потенциал молодой человек. Она может поддерживать или, напротив, чинить препятствия амбициям, заявленным молодым человеком. Благосклонность социума выражается в предоставлении поля деятельности юноше или девушке, вступающей в трудовую жизнь. Государство стимулирует подготовку нужных специалистов, у работодателей имеются в наличии рабочие места, у молодого специалиста есть возможность совершенствоваться в профессиональном мастерстве. Но если молодой человек настойчиво стремится воплотить себя в деле, где есть переизбыток желающих проявить себя, обострена конкуренция, а общество не создает льготных условий для роста, то у молодого человека есть риск растратить силы на бесполезные попытки устроить свою деловую карьеру. Особенно это касается юношей и девушек, жаждущих славы на театральных подмостках, в индустрии моды и прочих подобных сферах деятельности. Резюме в обсуждении животрепещущей гуманитарной темы представляется в виде «формулы» успешной деловой карьеры:

$$
\mathrm{Уc}_{\mathrm{c}}=И_{\mathrm{H}} \times \text { Пд } \times \text { Акт, }
$$


где Ус - степень достижений в профессиональном мастерстве специалиста; Ин - интерес как ведущий мотив деятельности; Пд - поле деятельности, совокупность условий, предоставляемых обществом для ее осуществления; Акт - степень усилий молодого человека для реализации целей личностного образовательного проекта. Глубинные смыслы этих условных обозначений для молодого человека все более раскрываются со временем.

Тема деловой карьеры была предметом обсуждения при проведении педагогического практикума, в ходе которого учащиеся делали пробы своего участия в преподавательской деятельности с перспективой избрать ее в качестве своей будущей профессии. Эта группа слушателей готовилась с учетом осознанной модели обучения, основанной на эргатическом подходе. В других группах дополнительного образования, ориентированных на техническое проектирование, отрабатывалась модель трудового коллектива. Его участники осваивали позиции коллективного субъекта деятельности. При этом было отмечено, что отношения членов группы, которые вначале носили исключительно личностный характер, трансформировались в сторону укрепления деловых взаимодействий, обеспечивающих наибольшую эффективность совместной деятельности. Отдельно эти аспекты трудового воспитания будут затронуты более подробно в последующих публикациях.

\section{Заключение}

В цикле наших работ $[2,7,8,9]$ были теоретически обоснованы и прошли эмпирическую проверку психолого-педагогические положения концепции обучения и воспитания, отвечающие личностным и общественным целям образования. Речь идет о четырех главных умениях, которыми должен овладеть выпускник школы: это умение учиться, умение трудиться, умение жить в обществе и умение стоить собственную жизнь. В качестве приоритетного направления исследования выбрано первое из названных, а именно - умение учиться самостоятельно. Известно, что реализация названных целей в практике работы образовательных систем поставило много вопросов, обусловленных теоретико-методологическим обеспечением образовательных технологий учащейся молодежи.

Федеральные государственные образовательные стандарты призваны внести определенность в концептуальные основы строительства образовательного процесса в средних образовательных учреждениях. В качестве таковых были названы системнодеятельностный подход и универсальные учебные действия (УУД). Однако и по прошествии 10 лет с момента введения в действие стандартов не удалось связать теоретические конструкты ансамбля научных теорий, задающих указанные подходы, и практику учебновоспитательного процесса в школе. Универсальные учебные действия 
оказались давно известными в педагогике общеучебными умениями. Их переименование не избавило педагогическую науку от поиска путей формирования соответствующих компетенций у школьников. Системно-деятельностный и культурно-исторический подходы, которыми авторы стандартов предложили руководствоваться учителям, методистам, авторам учебников, являются знаниями высшей степени абстракции. Их применение учителями в учебном процессе не представляется возможным. Прикладные науки, прежде всего психология образования, должны осуществить проекцию знаний философского уровня на нижележащий уровень образовательных технологий, изложив их на понятном педагогам конкретно-научном языке. Более того, это требование должно распространиться и на конечного потребителя образовательного результата - ученика, овладевшего умением учиться самостоятельно, или, другими словами, учащегося, ставшего для самого себя педагогом.

В наших исследованиях была поставлена именно такая задача. Потребовалась не только адаптировать знания, уже имеющиеся в арсенале гуманитарных наук. Необходимо было сохранить их эвристический потенциал и не допустить при этом вульгаризации и чрезмерного упрощенчества в изложении достаточно сложных, порою философских понятий. Кроме того, возникла необходимость дополнить их до целостной картины недостающими «паззлами» теоретического и прикладного знания, а именно:

- на теоретическом уровне прояснить вопросы содержания и структуры такого фундаментального понятия, как субъект учебной деятельности, которое должно выступить в качестве исходного при формировании всех видов активности учащегося;

- конкретизировать понятие «индивидуальная траектория развития», предложив его теоретическое содержание представить в виде модели саморазвития (личностный образовательный проект);

- определить состав метапредметных знаний, относящихся к сфере общенаучной методологии, обеспечивающей мыслительную деятельность обучаемых, и предложить методы и приемы их формирования.

Исследования осуществлялись на протяжении нескольких десятилетий в рамках национальных проектов, поддерживались грантами РГНФ и выполнялись в инициативном плане учеными МГУ. С 2012 г. экспериментальной базой исследования является Дмитровский институт непрерывного образования госуниверситета «Дубна» и Институт физической химии РАН (тематика - работы академических классов).

К настоящему времени задачи, поставленные в этом цикле исследований, в основном решены. В работе прошли эмпирическую проверку теоретические положения концепции формирования $\mathrm{y}$ 
школьников умения учиться самостоятельно. Это умение понимается как обретение учащимся комплекса педагогических компетенций, необходимых для управления собственной учебной деятельностью. Показано, что это умение может быть сформировано в подростковом и раннем юношеском возрасте в образовательной технологии, которую можно определить как опережающее обучение. Основным его назначением в системе образования является формирование рефлексивной включенности в процессы познания и личностного развития. «Сам себе педагог» служит девизом для учащихся, принимающих идею саморазвития как личностный императив.

В качестве дидактической опоры реализации концепции служит личностный образовательный проект, содержание которого выполняет опережающую функцию по отношению к объему знаний, предусмотренных программами основного, дополнительного и, что особенно важно, самообразования - важнейшего из видов получения знаний о мире и самом себе. Личностный образовательный проект имеет системную организацию, отраженную в модели «древа целей образования», которое ориентирует участников образовательного процесса в содержании педагогических компетенций, обеспечивающих умение учиться. В ходе его реализации предусмотрено формирование способности к самооценке себя как субъекта деятельности, развитие системного мышления, осознание общественных и личностных целей образования, а также путей их воплощения в жизнь. Выполнение личностного образовательного проекта позволяет обоснованно согласовывать цели и задачи основного и дополнительного образования для получения оптимального педагогического результата. Исследования завершилось подготовкой методических рекомендаций и освоением в педагогической практике в базовых образовательных учреждениях.

\section{Список литературы}

1. Jacobs G. Providing the scaffold: a model for early childhood/primary teacher preparation // Early Childhood Education Journal. 2001. Vol. 29. № 2.

2. Баринов В.К., Самоненко Ю.А. Педагогические компетенции учителя. Проблема содержания в образовательных технологиях будущего // Вестн. Твер. гос. ун-та. 2020. № 3.

3. Зинченко В.П. Психологическая педагогика: материалы к курсу лекций. Ч. І. Живое знание. Самара, 1998. 216 с.

4. Кочергина Н.В. Теоретико-методологические основы формирования системы методологических знаний при обучении физике в средней школе: монография. Благовещенск: Изд-во БГПУ, 2002. 230 с.

5. Леонтьев А.А. Образовательная система «Школа 2100». Педагогика здравого смысла. М.: 2003. 367 с.

6. Решетова 3.А. Формирование системного мышления в обучении. М.: Юнити-Дана, 2002. 344 с. 
7. Самоненко Ю.А. Учителю физики о развивающем образовании. М.: Изд-во Бином-лаборатория, $2011.285 \mathrm{c}$.

8. Самоненко Ю.А., Жильцова О.А., Самоненко И.Ю. Полисубъектная модель учебной деятельности как основа формирования педагогического мышления школьников // Вопр. психол. 2013. № 5. С. 81-92.

9. Самоненко Ю.А. Психология формирования профессионализма // Психология труда, инженерная психология и эргономика. М.: Юрайт, 2017. 529 с.

Об авторах:

БАРИНОВ Василий Константинович - кандидат педагогических наук, доцент, директор Филиала ГБОУ ВО Московской области «Университет «Дубна» - Дмитровский институт непрерывного образования (141801, Московская обл., г. Дмитров, мкрн ДЗФС, д. 23; 141800, Московская область, Дмитров, ул. Космонавтов, д. 33), e-mail: uni-dmitrov-otd@mail.ru

САМОНЕНКО Юрий Анатольевич - доктор педагогических наук, педагог дополнительного образования, научный сотрудник, научный руководитель лаборатории технического проектирования Филиала ГБОУ ВО Московской области «Университет «Дубна» - Дмитровский институт непрерывного образования (141801, Московская обл., г. Дмитров, мкрн ДЗФС, д. 23; 141800, Московская область, Дмитров, ул. Космонавтов, д. 33), e-mail: m.academia@mail.ru

\section{PEDAGOGICAL COMPETENCE OF THE TEACHER: THE PROBLEM OF METHODS AND FORMS OF TRAINING IN EDUCATIONAL TECHNOLOGIES OF THE FUTURE}

\section{V.K. Barinov, Yu.A. Samonenko}

The Institute of continuing education at Dubna State University, Dmitrov

The article examines the results of empirical testing of the effectiveness of the advanced learning technology of a student based on a personal educational project, the structure of which is represented by the model of the «tree» of education goals. Work on the project allows you to optimize the programs of basic and additional education for each student, as well as to determine his independent work. Methods and forms that contribute to the development of a student as a subject of educational activity, methods of forming thinking abilities, awareness of social and personal goals of education are substantiated. The directions of integration of types of education of students in preparation for professional activity in the field of science, high technologies and other areas of labor with high intellectual content are indicated.

Keywords: continuing education, scaffolding, personal educational project, advanced knowledge, methodological competence, system thinking, ability to learn, additional education. 